\title{
UNA PRIMERA APROXIMACIÓN A LA TRADICIÓN MÁGICA DE LAS GRUTAS MAGREBÍES A TRAVÉS DE AL-BAKRĪ Y AL-IDRĪSĪ
}

\author{
A First Approach to the Magical Tradition of the \\ Maghrebi Grottos through al-Bakrī and al-Idrīsi
}

Cristina Franco-Vázquez

Universidad de Salamanca. España

cristinafrancovazquez@usal.es | https://orcid.org/0000-0002-0402-9965

Fecha de recepción: 31/03/2020

Fecha de aceptación: 17/07/2020

Acceso anticipado: 26/09/2021

RESUMEN: La tradición magrebí del culto a las grutas se remonta a la época pre-islámica. La llegada del islam al norte de África supone la incorporación y transferencia de algunos de estos ritos a la tradición musulmana. Este tipo de ceremonias en grutas y cavernas encontradas en la tradición bereber (Bacax e Ifru), se pueden localizar también en la religión judía (Sefrou). La historiografía contemporánea (Doutté, Westermarck o Basset) ha elaborado una perspectiva general de la situación en la que se encuentran los rituales en el Norte de África en torno al s. xx. De estas obras cabe señalar la escasa atención a las ceremonias y rituales celebrados en cuevas. En cambio, sí destacan ciertas características de los mismos y clasifican las grutas y cavernas según el uso que le daba la población.

Esta contextualización, realizada a partir de las obras más modernas permite analizar a través de los relatos de los geógrafos árabes medievales, algunas leyendas y rituales relacionados con el culto en grutas.

En esta primera aproximación a la cuestión, se pueden resaltar varios aspectos. Estos van desde el léxico utilizado para denominar estas cuevas, además del tipo de animales y criaturas que habitan en ellas.

Palabras clave: Magreb; tradición islámica; cuevas mágicas; al-Bakrī; al-Idrīsī. 
ABSTRACT: The Maghrebi tradition of cave worship dates back to pre-Islamic times. The arrival of Islam in North Africa involves the incorporation and transfer of some of these rites to the Muslim tradition. This type of ceremonies in caves and caverns found in the Berber tradition (Bacax and Ifru) can also be found in the Jewish religion (Sefrou).

Contemporary historiography (Doutté, Westermarck or Basset) has produced an overview of the situation about the rituals found in North Africa around the $20^{\text {th }}$ century. Related to these works it is important to emphasize on the lack of attention to the ceremonies and rituals celebrated in caves. On the other hand, they highlight certain characteristics of these rituals and classify the caves and caverns according to the use that the population gave it.

This contextualization, made from the most modern works, allows us to analyze through the stories of the medieval Arab geographers, some legends and rituals related to the cult in caves.

In this first approach to the question, several aspects can be highlighted. These range from the lexicon used to name these caves, in addition to the type of animals and creatures that inhabit them.

Keywords: Maghreb; Islamic tradition; magic caves; al-Bakrī; al-idrīsī.

Sumario: 1. Los estudios del s. XX como antecedentes y contextualización del culto a las grutas; 2 . La tipología de Basset; 3. Las grutas magrebíes en los textos de Al-Bakrī y al-Idrīsī; 4. Conclusiones; 5. Referencias bibliográficas.

¡Sésamo, abre tu puerta! ${ }^{1}$

Las cuevas, así como las leyendas en torno a ellas, han formado parte de la historia de las religiones desde sus orígenes. Además de ser lugares de protección y refugio, eran emplazamientos destinados a la oración y, en no pocas ocasiones, en ellas se realizaban peticiones $u$ ofrendas a esos seres superiores a quienes la población encomendaba su alma.

Esta circunstancia no fue diferente en la tradición islámica, donde es habitual encontrar leyendas en torno a cuevas. Al centrar la atención en el Magreb, se aprecia que dichos cultos son esencialmente populares (Basset, 1920, p. 7). Estas creencias tienen una importante influencia de la tradición pre-islámica de origen popular. Fue la llegada del islam al norte de África la que permitió que algunos de estos ritos fueran incorporados a la tradición islámica.

En este trabajo se pretende analizar las leyendas y ritos relacionados con las cuevas en el ámbito magrebí. Para ello se contará con tres muestras de textos. En primer lugar, aquellos pasajes encontrados en dos fuentes árabes medievales, las obras de al-Bakrī y de al-Idrīsī. En segundo lugar, estudios realizados en el siglo XX, como lo son las obras del francés Edmond Doutté y el finlandés Edvard Westermarck,

\footnotetext{
${ }^{1}$ Vernet, 1990.
} 
quienes realizaron sendos trabajos de campo de gran relevancia en el estudio de la tradición cultural magrebí. Trabajos de campo que permiten conocer la existencia de prácticas tradicionales y cultos que han pervivido a lo largo del tiempo. Y, por último, aquellos documentos que nos permiten acercarnos a la tradición bereber que existía en el Magreb antes de la llegada del islam².

\section{LOS ESTUDIOS DEL S. XX COMO ANTECEDENTES Y CONTEXTUALIZACIÓN DEL CULTO A LAS GRUTAS}

El culto a las cuevas está documentado en el norte de África desde época preislámica y como parte de tradiciones ancestrales (Bénabou, 2005, pp. 268-271). La permanencia de prácticas de este tipo, vinculadas o no a algún tipo de culto, se documenta hasta las primeras décadas del siglo XX.

Sin embargo, remontándonos a épocas anteriores a la llegada del islam al Magreb, encontramos que las tradiciones y leyendas que veremos más adelante presentan grandes similitudes con la tradición bereber. Es conocido que estos espacios daban cabida a determinadas deidades, como sucede con Bacax, deidad adorada en una cueva; e Ifru, adorado en un refugio bajo una roca, sobre los cuales me detendré a continuación.

Bacax, o Bacax Augustus, es descrita por Gabriel Camps (1991) como una divinidad líbica que era adorada en una gruta de Ŷabal Taya, cerca de la ciudad de Guelma, en Argelia. Lo que correspondería con la antigua ciudad romana de Thibilis. Su culto, basado en sacrificios rituales, era practicado principalmente por los tuaregs de Ahaggar, al sur de Argelia, además de en el macizo de Aïr, en Níger, en el Sahara. Las celebraciones, según las inscripciones conservadas en dicha montaña, y fechadas en el siglo III, solían realizarse entre el final de marzo y el inicio de mayo.

También explica Camps que el nombre de esta deidad es muy conocido en la onomástica africana, encontrándolo como Bacques y Bacquax en inscripciones posteriores del siglo VII. Una teoría ofrecida por este autor acerca del origen del nombre Bacax esclarece que este puede derivar del topónimo Beccaca, aldea localizada en Adni, en la Gran Cabilia. Un dato que Ilama la atención y que explica Rosa M. Cid López (1987) es el hecho de que esta deidad gozaba de tal popularidad en época

2 Estos resultados que expongo a continuación se encuentran enmarcados dentro del proyecto coordinado de investigación MAGNA (Geografía cultural del Magreb y Dinámicas humanas en el Norte de África) (HAR2017-82152-C2-1-P), compuesto a su vez de dos subproyectos: por un lado, GEOMAGRED (Geografía cultural del Magreb Islámico Medieval y Moderno en la Red) y por otro DHUNA (Dinámicas humanas en el Norte de África) (HAR2017-82152-C2-2-P). El objetivo de ambos proyectos es el desarrollo de un portal web que permita crear un diccionario toponímico del norte de África y recabar información sobre grupos humanos, tribus y colectivos tanto árabes como bereberes. 
romana, que recibió el calificativo Agustus para, de esta manera, introducirla como deidad del pagus de Thibilis.

Continuando con la segunda deidad bereber subterránea, Ifru, explica también Camps (2001) que, en sus orígenes, no era el nombre de una divinidad. Especifica que fueron los historiadores de la antigua África quienes empezaron a reconocer a esta deidad tras haber sido vista una figura sobre una roca de Guechguech, emplazamiento localizado a $16 \mathrm{~km}$ al este de Constantina.

Este autor añade asimismo que la voz Ifru es muy parecida a la raíz ifri, que en bereber se refiere a una gruta, un refugio bajo la roca. A partir de dicha raíz, expertos como Ch. Tissot (1884), S. Gsell (1913) y Bénabou (2005) consideraron que Ifru es una divinidad de las cavernas.

Cabe destacar en este punto a los Banū Ifrān, pertenecientes a una de las cuatro ramas principales de los Zanāta y de quienes se dice que son descendientes de Ifri, nombre totémico que no pasó desapercibido para los propios historiadores musulmanes, porque ya Ibn Jaldūn (Lewicki, 1986, pp. 1039-1044) lo derivaba de esta voz amazige, con el significado de cueva, como se ha indicado. Aseguraba que había recogido los datos sobre este grupo de tres genealogistas bereberes de quienes se perdió toda información. Las primeras noticias que tenemos de este grupo bereber se remontan según el mismo autor, a la época de la conquista e islamización del Magreb, en torno al siglo I h / vil e. c.

Estas prácticas, tan habituales en la tradición bereber e islámica, se pueden apreciar también en el cristianismo y el judaísmo. De hecho, es célebre y significativa la llamada de atención de San Agustín a los cristianos norteafricanos con la que critica su hábito de culto con las montañas, subiendo a ella o descendiendo a sus subterráneos, para propiciar una mejor comunicación con Dios (Bénabou, 2005, pp. 268-271).

Por otro lado, explica Basset (1920) que en Sefrou ${ }^{3}$ se podían encontrar cuevas a las que la población judía acudía a realizar sus ofrendas y oraciones. Se confirma así que el culto en grutas no era una práctica exclusiva del islam y la tradición bereber, sino también del judaísmo.

Con todo, la historiografía contemporánea ha prestado menor atención a las tradiciones relacionadas con las cavernas, puesto que ha preferido centrarse en todos aquellos ritos relacionados con el fuego y el agua ${ }^{4}$. Ambos elementos eran utilizados como medio de purificación de las personas pertenecientes a las diferentes tribus o incluso de las cosechas y, por derivación, como medio para deshacer las desgracias o curar las enfermedades. Con ello trataban de alejar a los malos espíritus y traer la abundancia a sus tierras. En ocasiones, tanto el agua recogida

${ }^{3}$ Sefrú, ciudad del Marruecos central, situada a 29 km al sur de Fez, en la región de FezMequinez.

${ }^{4}$ Véase Westermarck, 2010; 1926; Doutté, 1909. 
en momentos concretos del año, como las cenizas producidas por el fuego, eran utilizadas como curas contra ciertos males y enfermedades.

En cualquier caso, y pese a la escasez de referencias, los estudios contemporáneos coinciden en mencionar unas regiones más propensas que otras para la realización de estos rituales, principalmente por el tipo de terreno en el que se hallan. Los suelos en los que se desarrollan solían ser calizos, fácilmente excavables que, en más de una ocasión, eran abiertos por las propias corrientes subterráneas que por allí discurrían. Esto daba lugar a la aparición cuevas que, aunque no eran demasiado grandes, resultaban adecuadas para este tipo de celebraciones.

Doutté y Westermarck, detallan en sus respectivas obras que los rituales solían realizarse anualmente y en unas fechas concretas. De igual modo, según relata Basset, las festividades podían alargarse incluso durante varios días. Sin embargo, a pesar de que hubiera días señalados en el calendario para estas fiestas, los fieles podían acercarse en cualquier momento del año. Es más, Basset (1920) indica que era bastante habitual que se acercaran allí para depositar sus ofrendas, pasando la noche en el lugar y que, a cambio de ellas, solicitaran indultos o realizaran alguna petición.

Asimismo, puntualiza que la población prefería mantenerse fuera de las grutas, por cuestiones meramente físicas: eran cuevas que solían tener un tamaño bastante reducido, por lo que los fieles no podían entrar en ellas. Los creyentes realizaban las ofrendas en la entrada de las mismas. Esto se debía a que, en muchas ocasiones, la cueva en cuestión era una pequeña abertura en una pared de roca (Basset, 1920, p. 8).

\section{LA TIPOLOGÍA DE BASSET}

Retomando el tema de los algares, uno de los aspectos de mayor relevancia en la obra de Basset es la tipología narrativa que ofrece al estudiar las leyendas e historias vinculadas a las cuevas y grutas mágicas. Establece cuatro grupos en los que clasifica, según su función, las cuevas que encontró durante la realización de su estudio.

El primer grupo está compuesto por todas las historias que hacen referencia a animales e incluso criaturas mágicas que habitan en estas cuevas. Este tipo de leyendas son muy habituales en el norte de África. Algunas de estas narraciones hablan incluso de personajes que se metamorfosean (Basset, 1920, pp. 13-28). En un intento por adaptar e incluir estas antiguas creencias en el islam, uno de los recursos más utilizados por la población fue la construcción de un relato en torno a un santo o santos enterrados en aquellas grutas (Basset, 1920, p. 8).

En el segundo grupo se incluyen todos los relatos que hablan de tesoros guardados en cuevas en las que, para poder entrar, se necesita utilizar una fórmula 
mágica (Basset, 1920, pp. 32-42). Además, según explica Basset, describen riquezas de inconmensurable valor, con tal cantidad de piedras preciosas que estas iluminaban la caverna. Con todo, no era primordial el oro o los tesoros albergados, sino algún talismán de muchísimo más valor y más preciado para las personas que entraban en ellas. Este tipo de cavernas eran buscadas y localizadas por magos que solían ayudarse de la población de los alrededores para encontrarlas. Una regla no escrita para este tipo de grutas es el hecho de que debía ser uno de los hombres que ayudaba al mago en la búsqueda de la cueva quien entrara a por el tesoro, pero nunca el propio taumaturgo. Una vez dentro de la cueva, esa persona debía ignorar todo el oro y las piedras preciosas para centrarse en conseguir el talismán de incalculable valor.

En este sentido, las narraciones sobre estas leyendas -en opinión de Bassetpueden sustentarse en una base real. En efecto, quienes poseían esas cantidades de oro y de piedras preciosas escondían sus propiedades en cuevas profundas para evitar que los ladrones las robaran. De igual modo, cabe destacar que, en época anterior a la llegada del islam, relatos similares tenían cierto peso en la tradición oral. En ellos se hablaba de una serie de genios que eran los encargados de proteger todas las fortunas subterráneas. Para acceder a ellas, la tradición bereber estipulaba una serie de rituales que había que realizar y en los que solía ser necesario un sacrificio, ya que era un tipo de magia que requería sangre.

El tercer grupo de cuevas establecido por Basset (1920) lo constituyen las cuevas de los oráculos. Estos, a su vez, se subdividen en dos tipos. El primero de ellos era el de los oráculos que daban una respuesta indirecta a través de la práctica de la incubación, que resultaba ser lo más frecuente. La visita a la caverna - o santuario- seguía un procedimiento que se iniciaba cuando una o varias personas realizaban una peregrinación para hacer una petición. Estas peregrinaciones solían durar entre dos y tres días habitualmente, y allí mismo se realizaba una ofrenda. Antes de volver a sus lugares de origen, quienes hacían la peregrinación debían pasar la noche en ese mismo lugar para que, mientras dormían, Dios les enviara la revelación que necesitaban. A este proceso de pasar la noche en una cueva y de recibir de Dios la respuesta a sus plegarias a través del sueño se denominaba incubación.

El segundo tipo de oráculos eran menos habituales. Se trataba de cuevas que daban una respuesta directa a las preguntas planteadas por quienes hacían las ofrendas. Estas preguntas se realizaban a través de un intermediario y de un modo muy simple: si en la cueva se producía algún tipo de ruido, se consideraba que la respuesta a dicha pregunta era afirmativa; si por el contrario permanecía en completo silencio, se consideraba que la respuesta era negativa.

Finalmente, existe un cuarto tipo de cuevas de suma importancia, denominadas cuevas de curación, que se consideraban sagradas (Basset, 1920, pp. 70-78). Generalmente solían ser oráculos a los que se acudía en busca de una cura terapéutica. El poder consultado era quien indicaba al solicitante el remedio necesario para 
sanar. Para ello se realizaba una incubación terapéutica. Dicha incubación seguía el mismo procedimiento descrito anteriormente, si bien la solicitud que se hacía iba encaminada a buscar una cura. En la práctica, muchas de estas cuevas-oráculos se convirtieron en grutas de curación ya que la población acudía en busca de un remedio cuando las curaciones habituales no surtían efecto.

A partir de esta clasificación propuesta por Basset, cabría establecer, siguiendo su tipología y según mi criterio, un quinto grupo. En este se incluirían los relatos relacionados con cuevas que podrían denominarse malditas; a saber: cuevas que los propios geógrafos árabes describen como lugares a los que nadie quiere acercarse porque quienes iban allí nunca regresaban, y cuevas en las que se habría producido un suceso atroz. Sobre ellas volveré más adelante.

En cualquier caso, la categorización de Basset es muy detallada y precisa y quizá en futuros trabajos sobre geógrafos árabes pueda encontrar numerosas muestras que se correspondan con su modelo. Para este estudio, me centraré, como ya he dicho, en las obras de al-Bakrī (siglo XI) y al-Idrīsī (siglo XII), cuyos textos proporcionan escasos ejemplos, aunque no por ello menos interesantes. Seguidamente, abordaré la relación de los relatos medievales y la tipología de Basset. Por otra parte, he de advertir que al final de todos los ejemplos de ambos geógrafos, abordaré la relación de estos con la tipología de Basset.

\section{LAS GRUTAS MAGREBÍES EN LOS TEXTOS DE AL-BAKRĪ Y AL-IDRĪSĪ}

Antes de analizar los distintos ejemplos encontrados en las obras de estos dos autores, es necesario advertir que las grutas magrebíes mencionadas por ellos son completamente distintas. No hay ninguna referencia en al-Idrīsī de las cuevas que recoge al-Bakrī, lo que permite suponer que ambos tuvieron fuentes distintas o informantes que no siguieron itinerarios similares.

Se aprecia que las primeras menciones halladas se remontan a la época de alBakrī. Es a principios del siglo XI cuando este autor cita, en su Kitāb al-masālik waI-mamālik, dos narraciones relativas a cuevas vinculadas con algún tipo de magia.

La primera de las historias (al-Bakrī, 1992, p. 714; 1911-1913, p. 113), se ubica en la montaña de Zīgīizì, localizada entre la ciudad de Biskra y Tébessa, en Argelia. La información es recogida por al-Bakrī a través de Aḥmad b. 'Umar b. Anas (al'Udrīi. CSIC), quien lo recopiló de Qāsim b. 'Abd al-'Azīz. El geógrafo andalusí relata que en dicha montaña había una cueva (kahf), en la que se encontraba el cadáver de un hombre que había sufrido una muerte violenta. Lo sorprendente era que, aunque habían pasado varios siglos desde que sucediera este acontecimiento, aún sangraban las heridas del cadáver, de tal manera que parecía que el crimen se había cometido apenas unos días antes. Debido a que se trataba de un lugar alejado de las poblaciones que se encontraban en los alrededores, la gente aseguraba que no 
sabía cuándo mataron a ese hombre. Sin embargo, todos los testimonios aseguraban que llevaba ahí toda la vida. Algunos de ellos explicaban que, años antes, gente de los enclaves circundantes cogieron el cuerpo y lo enterraron cerca de sus casas, ya que creían que era un santo que traería felicidad a los habitantes. Pero al poco tiempo de terminar, volvieron a la caverna y encontraron el cuerpo allí, de nuevo, como si nunca lo hubieran sacado.

Asimismo, al-Idrīsī (al-Idrīsī, 2002, p. 264 y Bresc, H. y. Nef, A., 1999, p. 170) también menciona la ciudad de Biskara o Biskra, cerca de la ciudad de Sfax. Da una breve descripción sobre ella y su prosperidad. No obstante, no realiza mención alguna sobre la montaña de Zì̀ìizì. Lo mismo ocurre en obras posteriores. El trabajo de Yāqūt (s. XIII) $)^{5}$ tampoco hace mención alguna a la montaña ni a la ciudad de Biskra.

Al continuar la lectura de al-Bakrī, se menciona en la región de Bilād al-Sūdān, concretamente en Zafqū, una segunda cueva (mag்āra), muy relacionada con la religión profesada por la población local (al-Bakrī, 1992, p. 870; 1913, p. 326). El geógrafo explica que basaban sus creencias en la adoración de una gran boa ( $\underline{t} u$ 'bān), con crin y cola, y la cabeza como la de un camello. Este gran animal vivía en el desierto, en una caverna cuya entrada se encontraba cubierta de follaje y piedras. Cerca de dicha entrada había una casa habitada por gente devota de su culto. La gente de allí -según lo relatado por el geógrafo-, decía que este gran animal era el encargado de elegir al gobernante del lugar. Por ello, cuando un dirigente moría, la población reunía a todas las personas que el pueblo consideraba dignas del trono ante esa gran serpiente, y pronunciaban una fórmula mágica que, en palabras de al-Bakrī, era desconocida para quienes no pertenecían al grupo. Una vez realizada la recitación, la serpiente se acercaba a todos los candidatos y los olía, hasta que golpeaba a uno de ellos con la nariz, quien era el elegido. Después de esto, la serpiente volvía a su cueva y la persona designada debía perseguirla para arrancar algunos pelos de la cola o el pelo del cuello del animal. El número de pelos que consiguiera coger el elegido indicaba el número de años que reinaría. Según el geógrafo andalusí, quienes practicaban este ritual aseguraban que era un método infalible para garantizar la elección.

Cabe destacar que, a pesar del gran detalle con el que narra al-Bakrī esta historia, este topónimo no es mencionado ni por al-Idrīsī ni, posteriormente, por Yãqūt en sus obras.

El Kitāb Nuzhat al-Muštāq fi Ihtirāq al-Āfāq de al-Idrīsī ofrece información sobre un número mayor de cuevas y cavernas, algunas de las cuales son descritas sin

${ }^{5}$ Yāqūt al-Ḥamawī (2012). Mu'ŷam al-Buldān (F. 'Abd al-'Azīz al-Ŷundī Ed.) Beirut: Dār alKutub al-'Ilmiyya. Ni en los tomos II y III de esta edición aparece estos lugares como entradas del diccionario. En las sucesivas menciones a Biskra al ocuparse de otros topónimos, Yāqūt tampoco alude a la montaña en cuestión. 
referencia alguna hacia lo mágico o prodigioso. Es el caso de las cuevas localizadas en la isla de Qerqena (al-Idrīsī, 2002, p. 304; 1999, pp. 204-205.). Tal como se aprecia en los textos, eran conocidas con el nombre de grutas (kuhüf y ġayrān) de Qarbadi y se podían localizar cerca del Qașr Ziyâd, castillo ubicado en el extremo más occidental de la isla. Eran utilizadas por la población como refugio cuando se producían invasiones.

La isla de Qerqena, conocida también en la actualidad como las islas Kerkennah $^{6}$, aparece mencionada en la obra de al-Bakrī, aunque, como vimos anteriormente, este geógrafo solo hace una breve mención de la isla de Qerqena, si bien no habla sobre sus cuevas protectoras (al-Bakrī, 1992, p.669). Yāqūt (2012), que sigue a al-Bakrī al hablar de esta isla, no alude a las cuevas que en ella encuentra al-Idrīsī.

La primera caverna con un componente mágico se puede localizar en la montaña de al-Mandib, en la región más oriental de África, en Eritrea (al-Idrīsī, 2002, p. 50 y Amédée Jaubert, 1836, pp. 46-47). Su mención es breve pero significativa: quien entra en ella no vuelve a salir. Aunque del texto se deduce una explicación sobrenatural por los testimonios recogidos, al-Idrīsī no explica el motivo, ni el origen de la misma y, por ello, no puede establecerse el peso específico del elemento prodigioso ligado a dicha caverna. Debe tenerse en cuenta, no obstante, que puede tratarse simplemente de una mera cuestión geográfica natural como, por ejemplo, que dicha caverna fuese tan escarpada que provocara que una vez que alguien entrara allí le resultara imposible salir, o incluso que dicha persona falleciera al caerse por alguno de los precipicios.

Probablemente, debido a la breve mención que realiza al-Idrīsī sobre esta historia, no haya sido lo suficientemente relevante para que Yãqūt lo pusiera por escrito. Al-Bakrī (1992) no llega a escribir en esta obra sobre una región tan oriental como es Eritrea, por lo que no recoge información del territorio.

La siguiente cueva mencionada por al-Idrīsī, ya en territorio magrebí, se localiza en la montaña de Lūniya, en el desierto del Nisar, si bien dichos topónimos ofrecen variantes en la traducción francesa (al-Idrīsī, 2002, p. 111 y al-Idrīsī, 1999, p. 105): la montaña de Lūkia y al desierto de Tiser. Este desierto, según el texto árabe, se puede localizar en la ruta que pasa por Aġmāt, Siŷilmasa y Dar'a. Allí habitaban unas serpientes - cuyo gran tamaño llama la atención del geógrafo-, las cuales atacan a quienquiera que suba a la montaña.

A priori parecería que el factor mágico quedaría fuera de contexto en este caso. Pero personalmente me inclino a pensar que es la propia serpiente la que da sentido al mismo. El término utilizado por el geógrafo árabe para designarla es țu'bān. Aunque cabría la mera acepción de "serpiente»" otras traducciones podrían ser

${ }^{6}$ En la actualidad, estas islas pertenecen a Túnez.

7 Véase, por ejemplo, Tlili, 2012, pp. 263 del apéndice uno, que recoge las dos citas coránicas de esta voz (Corán, VII: 107 y Corán XXVI: 32). 
asimismo "dragón» o "basilisco» que, dado el valor simbólico de estos animales, realza el componente prodigioso con independencia de que este tipo de elementos necesiten un análisis a posteriori de cara a su inclusión en la tipología de Basset.

Por otra parte, aunque no sea objeto de este trabajo, es interesante destacar que la presencia de estos reptiles en los textos geográficos permite enlazarlos con la tradición amazige - y por lo tanto magrebí- a través de sus cuentos. La serpiente es un elemento recurrente que aparece en múltiples relatos, como sucede, por ejemplo, en dos muy representativos: el de La tortuga, la rana y la serpiente, y el de La mujer, el rey y la serpiente (Basset, 1887). En el primero de ellos, correspondiente al género de las fábulas, la serpiente aparece retratada en un primer momento como un animal que trata de ayudar a la tortuga, si bien su naturaleza malvada se pone de manifiesto en el desenlace final, en el que devora a la rana. En el segundo, en cambio, se presenta a la serpiente como chivo expiatorio de un dragón que es el verdadero asesino de los dos hijos de una mujer protagonista de la historia. A pesar de ello, cuando el animal ha de responder ante el rey por estos crímenes, se acusa a sí misma y recibe el poder de Dios para comunicarse con los humanos. Esta interacción de los ofidios con el género humano y la representación de su naturaleza -a menudo dañina, aunque este caso sea una excepción - constituye el hilo conductor de no pocas narraciones populares norteafricanas que se filtran en tradiciones de las élites más cultas como es el caso de los geógrafos.

Con respecto a su aparición en textos de otros autores, al-Bakrī (1992) no hace mención alguna de la montaña o el desierto en el que se encuentra la misma. En este sentido, resulta asimismo interesante la siguiente leyenda que recoge al-Idrīsī y se localiza en la isla de Mustaškīn (al-Idrīsī, 2002, p. 218 y al-Idrīsī, 1999, pp. 126127). Según cuenta este relato, Du I-Qarnayn ${ }^{8}$, en una sus expediciones, llegó a la isla de Mustaškīn. A su llegada descubrió, gracias a los habitantes de la zona, que allí vivía un enorme dragón (tinnīn) que se alimentaba de lo que cazaba, ya fueran animales salvajes, animales domésticos o habitantes. Para vivir en paz con el dragón, la población debía entregarle diariamente el tributo de dos toros que dejaban en la entrada de la cueva en la que vivía el dragón.

Ante esta situación, Du I-Qarnayn decidió engañar al dragón. Para ello, primero le dio dos carneros en vez de dos toros. Al ser una cantidad menor de comida, el animal no sació su hambre. Repitió este proceso durante dos o tres días, de manera que el dragón, a cada día que pasara, tuviera más necesidad de alimento. Entonces Du l-Qarnayn decidió darle dos toros a modo de tributo de nuevo, el dragón se los comió de inmediato, sin apenas fijarse en ambos animales. Pero los dos habían sido desollados previamente y se había añadido en su interior una mezcla de azufre,

8 La figura de Dūl-Qarnayn o Alejandro Magno aparece en la tradición musulmana, según apunta Hernández Juberías (1996, pp. 22-24), al ser mencionado en la azora XVIII, 82-98 del Corán. 
aceite, cal y arsénico. Esta combinación, al contacto con el fuego del estómago del dragón, empezó a arder, quemando al animal desde dentro. Aunque intentó vomitar para expulsarlos, Du I-Qarnayn, previendo esta treta, había introducido dentro de los dos toros unos ganchos que se quedaron atravesados en la garganta del dragón, y le impedían hacerlo. De esta manera, cuenta al-Idrīsī, que el dragón se empezó a quemar desde dentro hasta que murió.

Asimismo, en esta historia resulta interesante el significado del nombre de la propia isla. Mustaškīn se podría traducir como "los que se quejan». Llama la atención que este nombre esté relacionado con la historia que al-Idrīsī relata sobre lo sucedido en la misma. Ello se ve reflejado también en los nombres de otras islas, como ocurre con la Isla de Sa'ālī, «de las ogresas», ya que

Hay seres que se parecen a las mujeres; sus dientes salen de sus bocas, sus ojos brillan y sus piernas parecen madera quemada; hablan un lenguaje ininteligible y hacen la guerra contra los monstruos marinos. Con la excepción de los genitales, no hay diferencia entre los dos sexos, ya que los hombres no tienen barba y su ropa consiste en hojas de árbol. (Amédée Jaubert, 1999, p. 126).

Otro claro ejemplo es la Isla de Jusrān. La «Isla de la Perdición», denominada así porque esta isla se encuentra «dominada por una alta montaña al pie de la cual viven hombres de color marrón, de pequeño tamaño y que usan una barba que cae de rodillas» (Amédée Jaubert, 1999, p. 126).

\section{CONCLUSIONES}

Aunque los textos geográficos de al-Bakrī y al-Idrīsī son distintos, ambos tienen tres elementos comunes: las cuevas, las serpientes y el ataque de estas últimas a las personas. Sin embargo, la tipología de Basset, incluso ampliada en el quinto grupo, como era mi propuesta, apenas si aparece reflejada conforme a los ejemplos recogidos. Los dos geógrafos se mueven en el grupo uno - la existencia de criaturas mágicas como la serpiente con crin y cola de caballo de al-Bakrī y el dragón de la historia de al-Idrīsī- si bien derivan luego hacia el grupo quinto en el que las cuevas se vuelven malditas, habida cuenta de que en ellas se relacionan las personas y la muerte, tema recurrente en este tipo de leyendas.

Hay que tener en cuenta en este punto un aspecto que considero de suma importancia. La clasificación de Basset se crea a partir de los testimonios encontrados por el autor sobre la región de Marruecos. Ese quinto grupo que añado a su clasificación es fruto de los pasajes analizados en todo el norte de África, una región más amplia. Ello me ha permitido encontrar testimonios más diversos que me proporcionan la información necesaria para crear ese quinto grupo. 
Sin embargo, resalta el hecho de que no existe alusión alguna a cuevas con tesoros mágicos, cuevas de oráculos o cuevas de curación. Tengo dudas acerca de si esta falta de información se debe a que los geógrafos no consideraban este tipo de cavernas relevantes para recopilar testimonios sobre ellas, o se debe a que no encontraron vestigio alguno de las mismas en las fuentes que consultaron.

Además de este aspecto, es relevante la terminología empleada por ambos autores a la hora mencionar las cuevas. Tanto al-Bakrī como al-Idrīsī emplean habitualmente las voces voz kahf y magära con significados difícilmente distinguibles. La primera hace referencia a una depresión del terreno, una cueva o incluso un precipicio mientras que la segunda, derivada de la raíz * $\dot{g} w r$ hace alusión a una cavidad o un lugar se encuentra más bajo que los terrenos circundantes o que absorbe el agua de la tierra. En los diccionarios, el término kahf ofrece varias posibilidades de traducción, siendo la más repetida la de caverna, seguida de la de gruta ${ }^{9}$. En cambio, el término maǵāra suele ofrecer las acepciones de cueva o cavidad ${ }^{10}$. Esta distinción terminológica no se ha reflejado en las versiones francesas que dan por hecho la sinonimia, lo cual, como es lógico, no ha de ser censurable. Pero conviene tenerla presente. Quizá trabajos futuros realizados al abrigo del proyecto de investigación del que formo parte arrojen luz sobre la abundante terminología de los geógrafos árabes para denominar elementos del paisaje natural (desiertos, tipos de agua dulce, territorios, grupos humanos, etc.). Otro término que aparece, aunque solo en una ocasión, es la palabra ġayrān, la cual se traduce por cavernas. Este término, con la misma raíz que mag்āra, ofrece las mismas dificultades en la traducción que el resto de los términos vistos hasta ahora.

La elección de estos términos no responde a ningún tipo de cuestión geográfica, probablemente responda a cuestiones de tamaño o tipo de espacio subterráneo. Se aprecia una falta de información y de descripciones de dichos espacios en las obras de los geógrafos. Debido a ello, en la actualidad desconocemos qué era lo que entendían los geógrafos por una cueva, una caverna y una gruta. Es muy probable que este sea el motivo principal de que dichos términos hayan dado lugar a interpretaciones.

${ }_{9}^{9}$ Véase Corriente, 2005, p. 1328; Dozy, 1927, p. 877, habla de una traducción bastante distinta: precipicio; Kazimirski, 1860, p. 939 explica que este término, que traduce por gruta o caverna, es sinónimo de maġära; Cortés, 1996, p. 1333, donde la voz kahf hace alusión a caverna, depresión o cavidad.

10 Diccionarios utilizados: Corriente, 2005, p. 1328, en el que el término $\dot{g} a \bar{r}$ se traduce como hueco, cavidad, cueva o cuenca; Cortés, 1996, p. 1333, donde la voz ġār hace alusión a cueva o cavidad; Dozy, 1927, p. 877, da una descripción en vez de realizar una traducción como tal, explica que se trata de un lugar que absorbe el agua para la tierra; Kazimirski, 1860, pp. 515-516, redacta, al igual que Dozy, explica que este término hace referencia a un terreno plano y más bajo que los lugares circundantes. 
Directamente ligada al problema terminológico está la dificultad para localizar en no pocos casos los topónimos mencionados, lo cual impide seguir la pista de tradiciones locales u otras tradiciones o testimonios que podrían ofrecer más elementos comunes. Al desconocimiento geográfico se unen la distancia temporal entre al-Bakrī y al-Idrīsī y sus relatos distintos, lo que invita a pensar que ambos tuvieron asimismo fuentes distintas para recopilar su información.

Con respecto a la información facilitada por al-Bakrī, ha sido más fácil localizar de manera aproximada las dos montañas que menciona, ya que la ciudad de Biskra, en la que se localiza la montaña de Zīgīzī, existe actualmente y se localiza al NE de Argelia. Lo mismo ocurre con Bilād al-Sudān. La localización de esta región histórica ha pervivido a lo largo de los siglos. Es muy probable que el hecho de que estos lugares aparezcan mencionados en más obras esté relacionado con que dichos lugares eran zonas concurridas o zonas de paso. En el caso de Biskra, este emplazamiento era un oasis al oeste del Sahara. El agua del lugar favorecía los movimientos de población en este espacio (Depois, 1986, pp. 1246-1247). En el caso de Bilād al-Sūdān, en esta región había numerosas rutas caravaneras destinadas al comercio transahariano (Kaye, 1997, pp. 752-761).

Con relación a los datos aportados por al-Idrīsī, se aprecia que solo es posible localizar en la actualidad una de sus menciones de cavernas. Estas son las grutas de Qarbadi, localizadas en la isla de Qerqena, la cual actualmente continúa existiendo con un nombre que apenas ha variado. Respecto a los otros tres lugares mencionados por el geógrafo, no he encontrado ningún tipo de referencia que me permita localizar geográficamente en la actualidad estos emplazamientos. Podría hacerse una ubicación aproximada de la montaña de Lūniya, ya que al-Idrīsī menciona a los Zaġāwa en esta región. Este grupo es localizado por al-Bakrī en Ifrīqiya. En la actualidad, quedan reductos de este pueblo en la frontera entre Chad y Sudán (Norris, 2002, pp. 384-385). Asimismo, Yāqūt menciona a los Zaḡāwa ubicándolos al sur de Marruecos y originarios de Sudán (Yāqūt, 2012, pp. 159-60).

Y, por último, habré de destacar asimismo la ausencia de rituales o prácticas similares a las narradas que hayan pervivido hasta fechas más recientes. En cualquier caso, al estar todavía en una fase muy incipiente de mi investigación, no descarto que en un futuro pueda localizarlos en monografías específicas u otras fuentes geográficas.

\section{REFERENCIAS BIBLIOGRÁFICAS}

al-Bakrī. (1911-1913). Description de l'Afrique septentrionale par Abou-Obeïd-ElBekri (M. G. De Slane, Trans. M. G. De Slane Ed.). Alger: Typographie Adolphe Jourdan. 
al-Bakrī. (1913). Description de l'Afrique Septentrionale (M. Gucking de Slane, Trans.). Alger.

al-Bakrī. (1992). Kitab al-Masālik wa-I-mamālik li-Abū 'Ubayd al-Bakrī (A. P. F. Van Leewen, André Ed.). Tunis: al-Dār al-'arabiyya li-l-kitāb - Bayt al-ḥikma.

Bresc, H. y. A., Nef (Ed.). (1999). al-Idrîîi. La prèmiere géographie de l'Occident. Paris.

al-Idrīsī. (2002). Kitāb nuzhat al-muštāq fī ihtirāq al-afāq. El Cairo.

Amédée Jaubert, P. (1836). Géographie d'Édrisi. Paris: L'Imprimerie royale.

Basset, H. (1920). Le culte des grottes au Maroc. Alger: Ancienne maison BastideJourdan.

Basset, R. (1887). Contes populaires berbères. Paris.

Bénabou, M. (2005). La résistance africaine à la romanisation. Paris: Editions La Découverte. https://doi.org/10.3917/dec.benab.2005.01

Camps, G. (1991). Bacax. En P. Publishers (Ed.), Encyclopédie berbère (Vol. 9, pp. 1297-1298). https://doi.org/10.4000/encyclopedieberbere.1244

Camps, G. (2001). Ifru. En P. Publishers (Ed.), Enciclopédie berbère (Vol. 24, pp. 3666). https://doi.org/10.4000/encyclopedieberbere.1547

Cid López, R. M. (1987). Oligarquías urbanas y cultos indígenas en el Norte de Africa: el ejemplo de las inscripiones de 'Bacax Augustus'. Memorias de historia antigua, 8, pp. 133-152.

Corriente, F. (Ed.). (2005) Diccionario avanzado árabe (2 ed.). Barcelona: Herder Editorial.

Cortés, J. (1996). Diccionario de árabe culto moderno. Madrid: Editorial Gredos

CSIC, Prosopografía de los ulemas de al-Andalus. ID:1433. https://www.eea.csic.es/ pua/

Depois, J. (1986). Biskra. En The Encyclopaedia of Islam (Vol. 2, pp. 1246-1247). London: Brill. 
Doutté, E. (1909). Magie et religion dans l'Afrique du Nord. Alger: Typographie Adolphe Jourdan.

Dozy, R. (Ed.). (1927). Supplément aux Dictionnaires arabes (2 ed.). Paris: Brill.

Gsell, S. (1913). Histoire ancienne de l'Afrique du Nord. Paris: Librairie Hachette et Cie.

Hernández Juberías, J. (1996). La península imaginaria: mitos y leyendas sobre alAndalus. Madrid: Consejo Superior de Investigaciones Científicas.

Kaye, A. S. (1997). Bilād al-Sūdān. En The Encyclopaedia of Islam (Vol. 9, pp. 752761). London: Brill.

Kazimirski, A. d. B. (Ed.). (1860). Dictionnaire Arabe-Français. Paris.

Lewicki, T. (1986). Ifran. En The Encyclopaedia of Islam (Vol. III, pp. 1039-1044). London: Brill.

Norris, H. T. (2002). Zaghāwa. En Encyclopaedia of Islam (Vol. 11, pp. 384-385). Londres: Brill.

Tlili, S. (2012). Animals in the Qur'an. New York: Cambridge University Press,

Tissot, Ch. (1884). La Province romaine d’Afrique. Encyclopédie berbère (Vol. 6, p. 487).

Vernet, J. (1990). Historia de Alí Babá y los cuarenta ladrones. En Las Mil y Una noches (Vol. II, pp. 1519-1563). Barcelona: Editorial Planeta.

Westermarck, E. (2010). Midsummer Customs In Morocco (Folklore History). Read Books.

Westermarck, E. (1926). Ritual and Belief in Morocco. London: Routledge Revivals.

Yāqūt al-Ḥamawī. (2012). Mu'ŷam al-Buldān (F. 'Abd al-'Azīz al-Ŷundī Ed.) Beirut: Dār al-Kutub al-'Ilmiyya. 
